\title{
Estudo da biodegradação de carcaças de aves por meio do processo de compostagem em biodigestores fechados descontínuos
}

\author{
Study of poultry carcass biodegradation through the \\ Composting process in closed discontinuous digesters
}

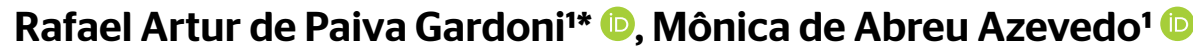

\begin{abstract}
RESUMO
O estudo da biodegradação de carcaças de aves por meio da compostagem em biodigestores fechados descontínuos possibilitou a avaliação da compostagem como forma alternativa para o tratamento dos resíduos sólidos gerados nas granjas. O estudo iniciou com a caracterização dos resíduos que seriam usados no processo e transcorreu por meio das análises e do monitoramento dos parâmetros identificados para avaliar o processo de compostagem dentro do biodigestor. A compostagem se mostrou satisfatória ao final do processo, sendo que todas as carcaças foram totalmente degradadas e não apresentaram riscos ambientais.
\end{abstract}

Palavras-chave: avicultura; carcaças; compostagem; resíduos sólidos.

\begin{abstract}
The study on poultry carcasses' biodegradation through composting in closed discontinuous digesters enabled the evaluation of composting as an alternative for the treatment of solid waste generated on farms. The study began with the characterization of the waste that would be used in the process and went through the analysis and monitoring of the identified parameters to evaluate the composting process inside the digester. The composting was found satisfactory at the end of the process, and all carcasses were totally degraded and did not present any environmental risks.
\end{abstract}

Keywords: aviculture; carcass; composting; solid waste.

\section{INTRODUÇÃO}

A produção mundial de carne de frango, segundo dados do United States Department of Agriculture (USDA), foi estimada em 81,137 milhões de toneladas, em 2011, sendo o Brasil o terceiro maior produtor, com 13,058 milhões de toneladas, precedido apenas pelos Estados Unidos e pela China, que ocupam o primeiro e o segundo lugar, respectivamente (UBABEF, 2012). A atividade apresenta papel expressivo na atual economia brasileira, gerando empregos diretos e indiretos. Os subprodutos da atividade humana têm constituído sérios problemas de poluição ambiental, associada à escassez de recursos naturais. Ao lado do crescimento dos índices produtivos, cresce também a preocupação com os efeitos das criações intensivas de aves sobre o meio ambiente, principalmente no que diz respeito à geração e à disposição dos resíduos produzidos (cama de frangos e carcaça de aves), considerando que a mortalidade média de aves é de 3,5\% (PERDOMO, 2001). Baseando-se nessa mortalidade média de aves durante toda a fase de engorda e considerando a produção brasileira de 13,058 milhões de toneladas de frango em 2011 e mundial de 81,137 milhões de toneladas no mesmo ano, podemos perceber a grande quantidade de carcaças que devem ter sido descartadas durante esse período de produção (UBABEF, 2012). A Figura 1 apresenta a produção brasileira de frangos nos últimos anos.

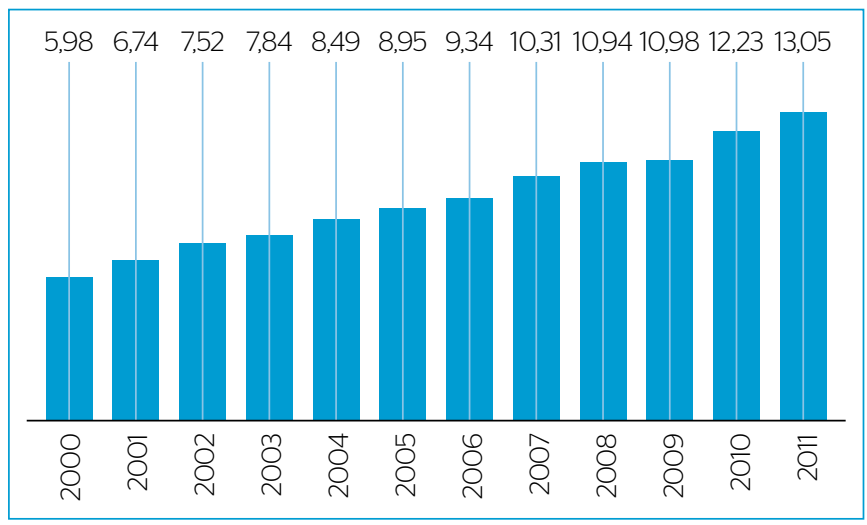

Figura 1 - Produção brasileira de carne de frango.

1Universidade Federal de Viçosa - Viçosa (MG), Brasil.

*Autor correspondente: telgardoni@hotmail.com

Recebido: 12/06/2013 - Aceito: 17/05/2018 - Reg. ABES: 118916 
Acredita-se que a maioria dessas carcaças tenha sido disposta de maneira inadequada, comprometendo o meio ambiente. Se as carcaças de aves resultantes da morte natural em níveis tão altos de produção não são eliminadas por meio de métodos ambientalmente aceitáveis, a expansão da indústria no futuro será limitada por restrições e ou leis regulamentares. Os métodos para a eliminação de carcaças de aves incluem o enterramento, a incineração e a compostagem. Esta é uma forma de tratamento relativamente barato e está ganhando ampla aceitação. Com o uso dos biodigestores, as carcaças, junto à "cama de frango", poderão ser transformadas em um composto orgânico com elevado potencial fertilizante, podendo ser comercializado ou utilizado nas propriedades.

O objetivo principal deste estudo foi o desenvolvimento de uma metodologia específica para a compostagem otimizada de carcaças de animais junto à "cama de frango" oriundas da agroindústria por meio de biodigestores fechados descontínuos com a produção de um composto orgânico de valor comercial ao final do processo. Pretende-se assim evitar problemas de saúde pública (proliferação de vetores de doenças) e ambientais (contaminação de águas superficiais e solo por chorume, entre outros).

\section{METODOLOGIA}

O processo de degradação das carcaças de frango ocorreu em duas etapas, sendo a primeira realizada no interior do biodigestor (degradação) e a segunda (fase de maturação) em pátio de compostagem. Todo o processo de degradação na primeira etapa foi descontínuo e fechado. Descontínuo, porque os resíduos foram depositados uma única vez no equipamento até o tratamento final; fechado, porque todo o processo ocorreu de forma a não deixar exposto o material durante a compostagem, evitando a contaminação do solo, a proliferação de vetores e o contato físico com as pessoas, a fim de garantir a biossegurança do processo de tratamento. O biodigestor foi construído com dimensões de $1 \times 1 \times 2 \mathrm{~m}$ e fundo vazado. A aeração forçada ocorreu por meio de lanças dispostas em pontos distintos ao longo da parede lateral do biodigestor, alimentadas por um ventilador centrífugo de alta pressão, com potência de $2 \mathrm{CV}$. A unidade também possuía sondas para controle de temperatura situadas na base, no centro e no topo do biodigestor. A fase de degradação teve duração de 49 dias no interior do biodigestor e mais 30 dias de maturação que aconteceu em pátio a céu aberto. A utilização dessa tecnologia teve como objetivo básico a aceleração do processo de degradação das carcaças de animais, formando, ao final do processo, um composto rico em húmus, o biofertilizante. A Figura 2 ilustra o equipamento utilizado no experimento.

Antes da realização do experimento foi necessário fazer a caracterização dos materiais utilizados no processo, pois para que a compostagem seja efetiva, alguns parâmetros devem ser avaliados e monitorados, como $\mathrm{pH}$, teor de água (umidade), tamanho das partículas, aeração, temperatura e nutrientes. O tratamento via compostagem utilizou os resíduos gerados nas próprias granjas de modo a garantir o desenvolvimento sustentável durante todo o processo. Os resíduos utilizados foram as carcaças de aves (morte natural), a cama de frango e a palha. Para conhecer as particularidades de cada resíduo e o funcionamento dos componentes do sistema de tratamento foi realizada a caracterização dos materiais de modo a garantir o funcionamento do processo. A Tabela 1 apresenta os resultados obtidos no processo de caracterização dos componentes antes de serem inseridos no protótipo.

Para a montagem do experimento foi adicionado no interior do biodigestor uma primeira camada de palha para promover a retenção de umidade e evitar o escoamento de líquidos, sobre a qual foram intercaladas camadas de cama de frango e de carcaças de aves. A quantidade de cama de frango utilizada foi suficiente para cobrir as carcaças, que foram dispostas com um pequeno espaçamento entre elas, a fim de se evitar a formação de zonas de anaerobiose. Para o monitoramento do experimento, foram coletadas amostras em diferentes pontos e

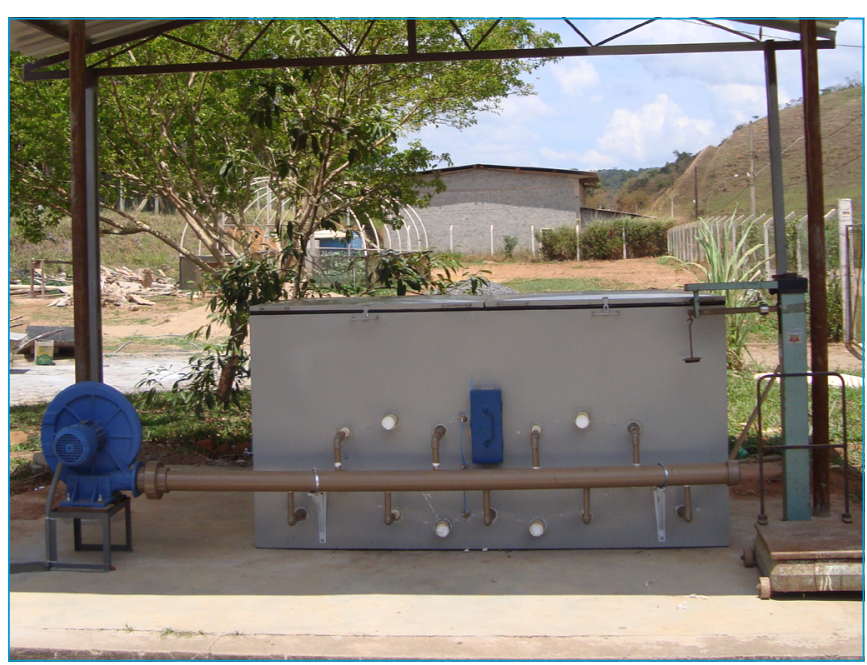

Figura 2 - Detalhe do biodigestor fechado descontínuo.

Tabela 1 - Caracterização dos componentes.

\begin{tabular}{l|c|c|c}
\hline Parâmetro & Cama de frango & Carcaças & Palha \\
\hline Umidade (\%) & 52,05 & 68,057 & 11,2 \\
\hline Sólidos totais voláteis (\%) & 88,53 & 91,523 & 96,45 \\
\hline Carbono (\%) & 49,18 & 50,846 & 53,58 \\
\hline Nitrogênio (\%) & 3,88 & 7,738805 & 0,6 \\
\hline C.N ${ }^{-1}$ & 12,68 & 6,57027 & 89,3 \\
\hline pH & 6,56 & 6,25 & 7,31 \\
\hline
\end{tabular}


profundidades do biodigestor, para que houvesse melhor representatividade do material amostrado do composto. Os parâmetros monitorados semanalmente foram: carbono orgânico total (COT), nitrogênio total Kjeldahl (NTK), relação carbono/nitrogênio (relação C.N-1), $\mathrm{pH}$, teor de água (umidade) e sólidos totais voláteis (STV). As análises microbiológicas foram realizadas após o período de degradação e no final da maturação, enquanto os metais, os nutrientes e a capacidade de troca catiônica (CTC) foram realizados somente após o tratamento total. A temperatura foi monitorada diariamente em três pontos distintos no interior do biodigestor.

O COT foi determinado pelo método Walkley-Black (GATTO et al., 2009) e a determinação de $\mathrm{N}$ foi baseada no Standard Methods método 4500-N. O método empregado para quantificação de coliformes totais e E. coli foi o do Substrato Definido Colilert ${ }^{\circledR}$ o-nitrofenil-b-D-galactopiranosídeo (ONPG) e 4-metilumbeliferil-b-D-glucuronídeo (MUG). Os metais e os micronutrientes foram obtidos utilizando-se o método 3030-I, do Standard Methods.

\section{RESULTADOS E DISCUSSÃO}

As experiências foram iniciadas para um ciclo de aeração de cinco minutos a cada 12 horas, sendo os resultados semanais expressos na Tabela 2 .

A variação na concentração de $\mathrm{C}$ refletiu a ação microbiana. Os valores iniciais de $\mathrm{N}$ se mostraram baixos em razão da dificuldade de a amostra representar toda a massa, em virtude de as carcaças serem dispostas de forma inteira, sem cortes. As carcaças se apresentaram com maior concentração de $\mathrm{N}$ do que a cama de frango e a palha. Assim, à medida que elas foram sendo decompostas, a concentração de $\mathrm{N}$ foi diminuindo. A relação adequada de $\mathrm{C}$ e $\mathrm{N}$ determina a velocidade de degradação da massa de resíduos. Segundo Henry (2003)

Tabela 2 - Primeiros resultados obtidos da biodegradação de carcaças de aves.

\begin{tabular}{|c|c|c|c|c|c|c|c|}
\hline \multirow[b]{2}{*}{ Amostra } & \multicolumn{7}{|c|}{ Análises } \\
\hline & $\begin{array}{l}\text { COT } \\
(\%)\end{array}$ & $\begin{array}{l}\text { NTK } \\
\text { (\%) }\end{array}$ & C. $\mathrm{N}^{-1}$ & $\begin{array}{l}\text { Umida- } \\
\text { de (\%) }\end{array}$ & $\begin{array}{l}\text { pH (em } \\
\text { água) }\end{array}$ & $\begin{array}{l}\text { STV } \\
\text { (\%) }\end{array}$ & $\begin{array}{c}\mathrm{CTC} \\
\left(\mathrm{cmol}_{\mathrm{c}^{\prime}} \mathrm{dm}^{-3}\right)\end{array}$ \\
\hline I & 48,07 & 3,03 & 15,84 & 56,10 & 8,48 & 86,53 & \multirow{8}{*}{ NA } \\
\hline$\|$ & 49,37 & 5,54 & 8,91 & 49,44 & 7,96 & 88,87 & \\
\hline III & 49,81 & 5,59 & 8,91 & 45,92 & 7,86 & 89,65 & \\
\hline IV & 48,30 & 4,45 & 10,85 & 33,96 & 8,20 & 86,93 & \\
\hline V & 47,18 & 4,00 & 11,80 & 29,80 & 8,01 & 84,92 & \\
\hline $\mathrm{VI}$ & 44,35 & 4,21 & 10,53 & 60,08 & 8,65 & 79.83 & \\
\hline VII & 41,94 & 3,16 & 13,27 & 61,00 & 8,22 & 75,50 & \\
\hline VIII & 42,68 & 3,38 & 12,63 & 57,24 & 8,75 & 76,83 & \\
\hline Maturação & 37,32 & 3,48 & 10,72 & 70,4 & 8,41 & 67,18 & 68,12 \\
\hline
\end{tabular}

COT: carbono orgânico total; NTK: nitrogênio total Kjeldahl; STV: sólidos totais voláteis; CTC: capacidade de troca catiônica; NA: não analisado. apud Paiva (2008), na compostagem de carcaça de animais, os valores iniciais adequados para a relação C. $\mathrm{N}^{-1}$ devem estar entre 10 e 20. De acordo com as primeiras análises, pode-se perceber que a relação C. $\mathrm{N}^{-1}$ se apresentou satisfatória durante o processo: mesmo iniciando com uma relação baixa, os resíduos se apresentaram totalmente degradados ao final do processo. Ainda de acordo com os autores, na compostagem de carcaças de animais a faixa ótima de teor de água seria entre 40 e $60 \%$. O teor de água foi corrigido ao longo do processo de modo que atendesse a umidade ótima, sofrendo variações ao longo da degradação. No período de maturação (que ocorreu em local aberto), a umidade se mostrou muito acima da faixa recomendada, mas isto ocorreu em razão do período de chuvas. Condições ácidas são prejudiciais aos microrganismos aeróbios reduzindo a velocidade da compostagem (GRAVES et al., 2000 apud PAIVA, 2008). Para a maioria dos microrganismos, a faixa ótima de $\mathrm{pH}$ está entre 6 e 8,0, facilitando, assim, a ação microbiana e aumentando a velocidade de degradação. Ao final do processo de compostagem, o composto formado tende a apresentar $\mathrm{pH}$ na faixa alcalina entre 7,5 e 9,0 (PEREIRA NETO, 2004).

Portanto, os resultados obtidos para $\mathrm{pH}$ demonstraram que esse parâmetro se enquadrou aos valores recomendados ao final do tratamento, sendo que os valores iniciais próximos a 8 indicaram degradação acelerada da massa de resíduos. A redução dos valores de STV indicou a transformação da matéria orgânica em material mineralizado. O decréscimo dos valores desse parâmetro indica a relação direta que há entre STV e COT, indicando o teor de matéria orgânica presente na massa de compostagem. A temperatura dentro do protótipo atingiu valores próximos a $75^{\circ} \mathrm{C}$, sendo esse parâmetro um reflexo da atividade microbiológica, em que valores elevados contribuem para a eliminação de organismos patogênicos, tornando-se um parâmetro crítico do processo de compostagem. $\mathrm{O}$ rápido aumento da temperatura nos primeiros dias indicou a degradação acelerada dos resíduos, conforme apresentado na Figura 3.

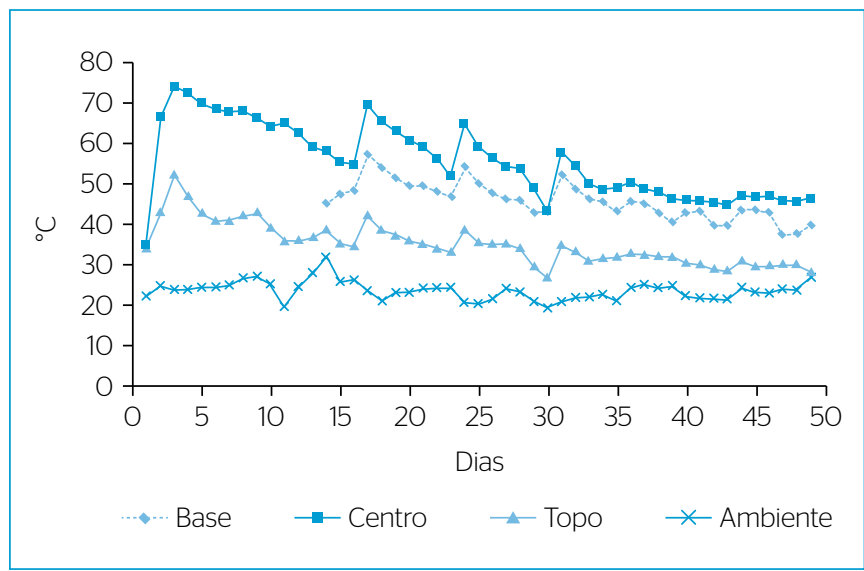

Figura 3 - Monitoramento da temperatura durante fase de degradação. 
Foram avaliadas as temperaturas em três zonas diferentes de modo a representar melhor toda a massa de resíduos. A temperatura foi controlada em uma faixa de $40 \mathrm{a} 60^{\circ} \mathrm{C}$, sendo que alguns autores indicam a temperatura ideal em torno de $55^{\circ} \mathrm{C}$. Os picos apresentados na Figura 3 foram decorrentes da correção do teor de água, sendo que a quantidade de água presente é essencial para que o processo de compostagem ocorra de forma adequada e acelerada. A CTC é um parâmetro utilizado para avaliar o grau de humificação do composto, uma vez que mede a capacidade do composto em absorver cátions, o que está diretamente relacionado ao índice de humificação do material. Segundo Kiehl (1998) apud Matos (2006), um bom composto deverá apresentar CTC de 60 a $80 \mathrm{cmol}_{\mathrm{c}} \cdot \mathrm{dm}^{-3}$. No experimento, a CTC foi avaliada somente ao final do tratamento, obtendo-se valor de $68,12 \mathrm{cmol}_{c} \cdot \mathrm{dm}^{-3}$, estando, portanto, de acordo com os valores considerados adequados para o composto orgânico, conforme preconizados por Kiehl (1998). O COT variou durante o período do experimento de 48 a 37\% (Tabela 2), havendo, portanto, redução de $22 \%$ durante todo período do tratamento. Paiva (2008), trabalhando com a compostagem de carcaça de frango pelo método das leiras estáticas aeradas, obteve reduções de médias de $29 \%$ em seus experimentos. Dessa forma, pôde-se verificar que o processo de compostagem foi eficaz no tratamento das carcaças e da cama de frango. Após passar pelo processo de tratamento, o material se apresentou com excelente qualidade, sob o ponto de vista microbiológico, por apresentar valores menores que 1 para coliformes termotolerantes, conforme apresentado na Tabela 3.

Espera-se, ao final do processo de compostagem, que todas as carcaças sejam totalmente degradadas e não apresentem riscos ambientais. Com a intenção de avaliar futuramente o potencial fertilizante

Tabela 3 - Resultados microbiológicos após tratamento no interior do biodigestor.

\begin{tabular}{l|c|c}
\multirow{2}{*}{ Análises (NMP.g-1) } & \multicolumn{2}{|c}{ Amostras } \\
\cline { 2 - 3 } Salmonella & Início da maturação & Final da maturação \\
\hline Coliformes totais & $2,5 \times 10^{2}$ & $\mathrm{NA}$ \\
\hline $\begin{array}{l}\text { Coliformes Termotolerantes } \\
\text { (Escherichia coli) }\end{array}$ & $2,1 \times 10^{1}$ & $1,6 \times 10^{2}$ \\
\hline Clostridium & $\mathrm{NA}$ & $<1,0$ \\
\hline
\end{tabular}

NMP: número mais provável; NA: não analisado. do material estabilizado, a Tabela 4 apresenta, em teores totais, os nutrientes e os metais encontrados nas análises realizadas ao final do processo de tratamento.

Os nutrientes e os metais encontrados ao final do processo de tratamento ratificam o potencial uso do composto orgânico como insumo agrícola. Segundo Mukhtar et al. (2004) apud Paiva (2008), o composto final produzido por meio do processo de compostagem de carcaças de animais apresenta uma série de nutrientes em sua composição, como $\mathrm{N}, \mathrm{P}, \mathrm{K}, \mathrm{Ca}, \mathrm{Mg}, \mathrm{S}, \mathrm{Mn}, \mathrm{Zn}$ e Cu, os quais foram confirmados pelas análises realizadas ao final do processo de tratamento, sendo observada também a presença de $\mathrm{Cd}, \mathrm{Cr}, \mathrm{Pb}, \mathrm{Ni}, \mathrm{Fe}$ e $\mathrm{B}$, provavelmente em função da alimentação fornecida nas granjas. A presença de metais pesados como $\mathrm{Cd}$ e $\mathrm{Pb}$ pode ser decorrente da tinta utilizada na pintura das paredes internas e na tampa superior do biodigestor, recomendando assim que estudos futuros realizem tais análises para comprovação dessa hipótese.

\section{CONCLUSÕES}

A compostagem é um processo biológico de reciclagem de nutrientes, podendo ser empregada desde que alguns parâmetros sejam adaptados para que as carcaças possam ser decompostas de maneira eficiente $\mathrm{e}$ segura, sem que haja disseminação de doenças, principalmente quando não se sabe a causa da mortalidade das aves. O emprego da compostagem justifica-se no tratamento e na reciclagem dos resíduos sólidos gerados em aviários e abatedouros de aves por acelerar a decomposição do material orgânico presente no conteúdo. O processo de biodegradação das carcaças de frango no biodigestor se mostrou satisfatório. Porém, há necessidade de os biodigestores serem operados sob diferentes condições, variando-se os diversos parâmetros que controlam a velocidade do processo de compostagem. Foi observado, ao longo dos trabalhos, que seria interessante a realização de outros trabalhos para avaliação da emissão de gases ao longo de todo o processo e também o potencial fertilizante do produto final gerado.

\section{FONTE DE FINANCIAMENTO}

Conselho Nacional de Desenvolvimento Científico e Tecnológico (CNPq), H3M soluções Ambientais e GIS.

Tabela 4 - Resultados das análises de caracterização do composto final.

\begin{tabular}{|c|c|c|c|c|c|c|c|c|c|c|c|c|c|c|c|}
\hline \multicolumn{16}{|c|}{ Análises } \\
\hline \multirow{3}{*}{ Composto } & $N$ & $P$ & $\mathrm{~K}$ & $\mathrm{Ca}$ & $\mathrm{S}$ & $\mathrm{Mg}$ & $\mathrm{Mn}$ & $\mathrm{Zn}$ & $\mathrm{Cu}$ & $\mathrm{Cd}$ & $\mathrm{Cr}$ & $\mathrm{Pb}$ & $\mathrm{Ni}$ & $\mathrm{Fe}$ & B \\
\hline & \multicolumn{6}{|c|}{$\%$} & \multicolumn{9}{|c|}{$\mathrm{ppm}$} \\
\hline & 3,5 & 3,0 & 2,3 & 3,8 & 0,8 & 1,2 & 914 & 117 & 121 & 0,6 & 4,2 & 15 & 6,7 & 4152 & 46,7 \\
\hline
\end{tabular}




\section{REFERÊNCIAS}

AMERICAN PUBLIC HEALTH ASSOCIATION (APHA). (2012) Standard Methods for the Examination of Water and Wastewater. 22 ed. American Public Health Association, American Water Works Association, Water Environment Federation. Washington, DC.

GATTO, A.; BARROS, N.F.; NOVAIS, R.F.; SILVA, I.R.; MENDONÇA, E.S.; VILLANI, E.M.A. (2009) Comparação de métodos de determinação do carbono orgânico em solos cultivados com eucalipto. Revista Brasileira de Ciência do Solo, v. 33, n. 3, p. 735-740. http://dx.doi. org/10.1590/S0100-06832009000300026

KIEHL, E.J. (1998) Manual de compostagem: maturação e qualidade do composto. Piracicaba. 171p.

MATOS, A.T. (2006) Prática de tratamento e aproveitamento agrícola de resíduos sólidos. Viçosa: Associação de Engenheiros Agrícolas de Minas Gerais, Departamento de Engenharia Agrícola da UFV. 43p. (Série Caderno Didático, n. 45).
PAIVA, E.C.R. (2008) Avaliação da compostagem de carcaças de frango pelos métodos da composteira e leiras estáticas aeradas. 163f. Dissertação (Mestrado em Engenharia Civil) - Universidade Federal de Viçosa, Viçosa.

PERDOMO, C.C. (2001) Controle do ambiente e produtividade de frangos de corte. In: REUNIÃO ANUAL DA SOCIEDADE BRASILEIRA DE ZOOTECNIA, 38., 2001, Piracicaba. Anais... Piracicaba. p. 91-110

PEREIRA NETO, J.T. (2004) Compostagem: fundamentos e métodos. In: SIMPÓSIO SOBRE COMPOSTAGEM: CIÊNCIA E TECNOLOGIA, 1., 2004, Botucatu. Anais... Botucatu: Universidade Estadual Paulista "Júlio de Mesquita Filho".

UNIÃO BRASILEIRA DE AVICULTURA (UBABEF). (2O12) Relatório anual 2012. São Paulo: UBABEF. Disponível em: <http://www.ubabef. com.br/publicacoes>. Acesso em: 18 abr. 2013. 